SCADidoc

International Journal of Dentistry and Oral Science (IJDOS)

ISSN: 2377-8075

\title{
Accuracy Of Various Apex Locators In Detecting Root Canal Perforation In Single Rooted Teeth - An In Vitro Study
}

Research Article

Mulumoodi Rama Sowmya ${ }^{1}$, Pradeep ${ }^{2 *}$

${ }^{1}$ Department of Conservative Dentistry and Endodontics, Saveetha Dental College and Hospitals, Saveetha Institute of Medical and Technical Sciences, Saveetha University, Chennai, India.

${ }^{2}$ Reader, Department of Conservative Dentistry and Endodontics, Clinical Genetics Lab, Saveetha Dental College and Hospitals, Saveetha Institute of Medical and Technical Sciences, Saveetha University, Chennai - 600077, India.

\section{Abstract}

Introduction: In Spite of the advancements made in endodontic techniques, few mishaps are bound to occur. The most common endodontic mishap is root perforation. A root perforation is defined as an artificial opening in the tooth crown or root area creating a communication between the root canal system with the periodontal tissues or oral cavity. Root perforations often compromise the success of root canal therapy. They pose a challenge to the clinician with the fact that they are mostly difficult to diagnose radiographically and also challenge the clinician in determining the location and size of the perforation. Ever since an electronic device to determine the working length has been introduced by Sunada, various reports have advocated the use of these devices to determine the perforation. EALs are touted to be reliable for detecting root perforations. There are six generations of electronic apex locators with specific functions.

Aim: The aim of this study is to comparatively evaluate the accuracy of three different apex locators in detecting the root perforation.

Materials and Methods: Ten extracted, single-rooted human teeth were perforated artificially in the middle section. The actual canal lengths (ALs) up to the perforation site were determined, and then the teeth were embedded in an alginate mold. A 10k file was inserted into the canal through the access cavity and then determination of perforation with the three apex locators (ROOT ZX, APEX ID, PROPEX PIXI) was made. The electronic measurements of the perforations were obtained using a size $10 \mathrm{~K}$-file by each EAL in various conditions. For each tooth, the AL was subtracted from the electronic length of the perforation.

Results: The mean values of Root ZX and Apex ID are lower compared to propex pixi implying that Root ZX and Apex ID detected perforation better compared to Propex pixi.The mean values of Root ZX(0.95+/-0.8) and Apex ID $(0.96+/-0.5)$ are lower compared to propex pixi(1.67+/-0.7) implying that Root ZX and Apex ID detected perforation better compared to Propex pixi.

Conclusion: Under the given conditions and with the electronic devices employed in this study, we were able to determine a root canal perforation in all cases. In the present study, Root ZX and Apex ID were able to give better results compared to Propex pixi.

Keywords: Apex Locators; Apex ID; Perforation; Propex Pixi; Root ZX.

\section{Introduction}

Root perforation is said to be an unnatural communication between the root canal to the supporting tissues of teeth. Although there are certain pathological causes of perforation such as infection, iatrogenic perforation is the most common cause. [1] It is one of the serious dental complications that can affect the prognosis of the treatment.[2] It occurs in 3-10\% of the root canal treatments. Due to these root perforation, chances of infectious microbes entering the canal are high. Hence it is important to treat the perforation site at the earliest. [3] There are many factors which can affect the healing of perforation which includes

*Corresponding Author

Pradeep,

Reader, Department of Conservative Dentistry and Endodontics, Clinical Genetics Lab, Saveetha Dental College and Hospitals, Saveetha Institute of Medical and Technical Sciences, Saveetha University, Chennai - 600077, India.

Tel: 9710404482

E-mail: pandu.pradeep@gmail.com

Received: May 04, 2021

Accepted: July 29, 2021

Published: August 02, 2021

Citation: Mulumoodi Rama Sowmya, Pradeep. Accuracy Of Various Apex Locators In Detecting Root Canal Perforation In Single Rooted Teeth - An In Vitro Study. Int J Dentistry Oral Sci. 2021;8(8):3624-3627. doi: http://dx.doi.org/10.19070/2377-8075-21000741

Copyright: Pradeep 2021. This is an open-access article distributed under the terms of the Creative Commons Attribution License, which permits unrestricted use, distribution and reproduction in any medium, provided the original author and source are credited. 
time of detection of perforation, size and location of perforation. Hence it is important to diagnose the perforation accurately. [4]

Diagnosis of root canal perforation consists of a combination of symptomatic findings, clinical observation and diagnostic aids. The diagnostic aids include radiographic assessment and use of electronic apex locators [5]. There are various methods to detect these perforations such as profuse bleeding from root canal during instrumentation and indirect evaluation of bleeding by paper points, radiographic assessment, and electronic apex locators (EALs). [6]

Radiographic assessment may not always be accurate in detecting perforation. Hence it is important to employ electronic devices to detect perforation. [7] Fuss et al demonstrated the limitations of radiographs in detecting the root perforations. [8] Initially, Kaufman et al 1976, Nahmias et al 1983 and Keil et al 1989 reported the ability of resistance based electronic apex locators in detecting perforation.[9]

Sunada was the first to introduce an electronic apex locator. Electronic apex locators have proved to be precise in determining the location of apical constriction, horizontal root fractures, and apical root resorptions. [10] Various reports have suggested that apex locators can be used for the detection of perforation. [11]

Older apex locators worked under the impedance principle. Newer apex locators work under different principles including gradient method, ratio method etc.[12] Different EALs have been recommended for the detection of perforation. Root $\mathrm{ZX}$ is the most sought after EAL which is based on the ratio type with dual Frequency (8 and $0.4 \mathrm{kHz}$ ).[13] Propex pixi is a fifth generation EAL and Apex ID is a fourth generation EAL.[14]

Previously our team has a rich experience in working on various research projects across multiple disciplines (Govindaraju and Gurunathan 2017; A. Christabel et al. 2016; Soh and Narayanan 2013; Mehta et al. 2019; Ezhilarasan, Apoorva, and Ashok Vardhan 2019; Campeau et al. 2014; Kumar and S 2016; S. L. Christabel 2015; Kumar and Rahman 2017; Sridharan, Ramani, and Patankar 2017; Ramesh et al. 2016; Thamaraiselvan et al. 2015; Thangaraj et al. 2016; Ponnulakshmi et al. 2019; "Fluoride, Fluoridated Toothpaste Efficacy and Its Safety in Children - Review" 2018) Now the growing trend in this area motivated us to pursue this project.

\section{Materials And Methods}

\section{Sample preparation}

Ten single rooted teeth were collected. Standard access cavity preparations were made and the incisal edges were flattened to achieve a reproducible reference point. The crown of each tooth was sectioned at the cemento-enamel junction using a diamond disc to establish a surface level to serve as a stable reference point for all the measurements.

\section{Preparation of artificial perforation}

A perforation of $0.5-1 \mathrm{~mm}$ was made in the middle third at 12 $\mathrm{mm}$ from the reference point using a carbide bur. A 10k file was inserted and allowed to be seen through the perforation site under stereo microscope $(25 \mathrm{x})$.

\section{Preparation of the alginate model}

Alginate was poured in a rectangular mould. The teeth were embedded in the alginate after the application of ECG gel onto the implantation site. To complete the electrical circuit, an indentation for the placement of lip clip was also made at the edge of the alginate model.

\section{Detection of perforation}

A 10k file was inserted into the canal and the apex locators were arranged accordingly to detect the perforation. The length at which the perforation was detected was noted.

\section{Results And Discussion}

The results of the present study showed that Root ZX and Apex ID gave better results compared to Propex pixi. The results are statistically significant. The mean values of Root $\mathrm{ZX}(0.95+/-0.8)$ and Apex ID $(0.96+/-0.5)$ [Table 1] are lower compared to propex pixi(1.67+/-0.7) implying that Root ZX and Apex ID detected perforation better compared to Propex pixi. Among the apex locators, Root ZX(p- 0.026) and Apex ID(p- 0.161) gave better results compared to PROPEX PIXI(p- 0.385) [Figure 1]

In root canal treatment, one of the unpredictable complications is root perforation. It presents a challenge to the clinician in terms of proper diagnosis of the perforation, determining its location and size and also assessing the prognosis of the tooth.[15] It is imperative to accurately diagnose the perforation in order to complete the treatment. Iatrogenic root perforations account for $2-12 \%$ of endodontically treated teeth.[16] Unfortunately, there is a lack of evidence based research concerning the diagnosis of root perforations upon which treatment decisions can be made. [17]

Perforations create an unwanted communication between the external oral environment with the tooth [18]. This communication forms a pathway for the entry of microbes from the oral environment into the tooth which can affect the prognosis of the tooth.

Figure 1. Stereomicroscopic view of perforation.

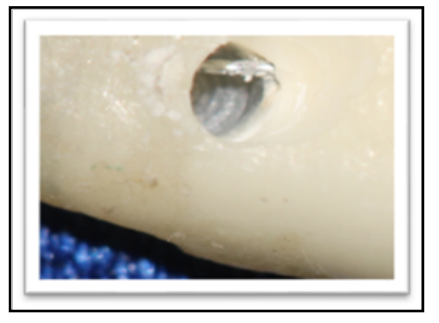


Figure 2. Bar graph depicting the comparison of three apex locators.

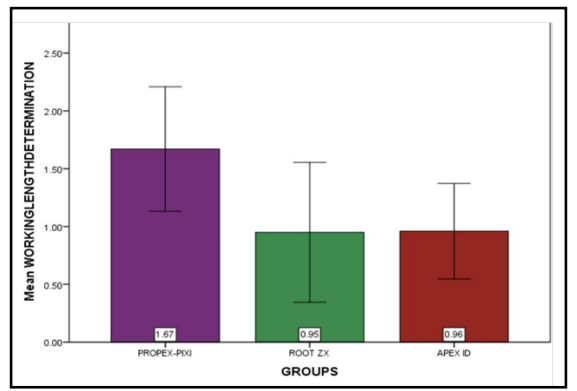

Table 1. Table showing the Mean and Standard deviation of the measurements recorded by the apex locators.

\begin{tabular}{|c|c|c|}
\hline GROUPS & MEAN +/- SD & N \\
\hline PROPEX PIXI & $1.67+/-0.7$ & 10 \\
\hline ROOT ZX & $0.95+/-0.8$ & 10 \\
\hline APEX ID & $0.96+/-0.5$ & 10 \\
\hline TOTAL & $1.19+/-0.7$ & 30 \\
\hline
\end{tabular}

$[19,20]$ Hence it is very important to treat the perforation at the earliest to prolong the life of the tooth [21]. Diagnosis of the perforation is important in order to treat the perforation. Clinical and radiographic imaging of the perforation may not be always accurate and reliable. Hence electronic devices such as apex locators can be used for this purpose [22].

Electronic apex locators have been prominent in detecting the apical constriction, determining the working length in curved canals. [23] Ching and Pitt Ford suggested the use of apex locators as an aid in diagnosing the perforation.[24] In this study, three different electronic apex locators have been employed to detect simulated perforation in single rooted teeth.[25]

Root ZX is a third generation apex locator based on dual frequency ratio type. Apex ID is a fourth generation apex locator based on measuring the resistance and capacitance separately. [26] Propex pixi is a fifth generation apex locator which is a multifrequency apex locator which also records capacitance and resistance separately but at multiple frequencies. [27]

The three devices were fully charged and used for detecting perforation in the present study.[28, 29] Electroconductive material such as alginate was used to simulate the conditions of the oral environment. The lip clip of the respective apex locators was thus inserted into the alginate model and the probe was inserted into the root canal and the length at which the perforation was detected was noted.[11]

The results of the present study showed that Root ZX and Apex ID gave better results compared to Propex pixi. The results are statistically significant. In a study conducted by Marroquin et al, five apex locators (ProPex II, Elements Apex Locator, Apex NRG, Raypex 5 and Raypex 6) were tested to detect root canal perforation with inserted metal posts. The study concluded that all the apex locators were able to detect perforation with high sensitivity and specificity.[2]

In another study conducted by Nasiri et al showed the percentage of accuracy of electronic working lengths, measured by Root ZX and Raypex 6, was $85.7 \%$ and $90.9 \%$ respectively whereas Raypex
6 was more accurate in determining the root canal perforation compared to Root ZX.[5]

In a study conducted Nazari et al, two apex locators ( SmarPex and NovApex) were compared in detecting apical perforation. [30] The statistical analysis showed reliable accuracy in detecting the apical perforation for the two electronic apex locators $(60 \%$ and $80 \%$ for NovApex and Smarpex, respectively).[4]

\section{Conclusion}

Under the given conditions and with the electronic devices employed in this study, we were able to determine a root canal perforation in all cases. In the present study, Root ZX and Apex ID were able to give better results compared to Propex pixi.

\section{References}

[1]. Poorni S, Srinivasan MR, Nivedhitha MS. Probiotic Streptococcus strains in caries prevention: A systematic review. J Conserv Dent. 2019 Mar;22(2):1238.

[2]. Marroquín BB, Fernández CC, Schmidtmann I, Willershausen B, Goldberg F. Accuracy of electronic apex locators to detect root canal perforations with inserted metallic posts: an ex vivo study. Head Face Med. 2014 Dec 23;10:57.Pubmed PMID: 25533476.

[3]. Jenarthanan S, Subbarao C. Comparative evaluation of the efficacy of diclofenac sodium administered using different delivery routes in the management of endodontic pain: A randomized controlled clinical trial. J Conserv Dent. 2018 May-Jun;21(3):297-301.Pubmed PMID: 29899633.

[4]. Nazari Moghaddam K, Nazari S, Shakeri L, Honardar K, Mirmotalebi F. In vitro detection of simulated apical root perforation with two electronic apex locators. Iran Endod J. 2010 Winter;5(1):23-6.Pubmed PMID: 23130025.

[5]. Nasiri K, Wrbas KT. Comparing the accuracy of two electronic apex locators in the determination of working length and the detection of root perforations: An in vitro study. Dent. 2019;5:1-5.

[6]. Rajendran R, Kunjusankaran RN, Sandhya R, Anilkumar A, Santhosh R, Patil SR. Comparative evaluation of remineralizing potential of a paste containing bioactive glass and a topical cream containing casein phosphopeptide-amorphous calcium phosphate: An in vitro study. Pesqui Bras Odontopediatria Clin Integr. 2019 Oct 10;19:1-10.

[7]. Nandakumar M, Nasim I. Comparative evaluation of grape seed and cranberry extracts in preventing enamel erosion: An optical emission spectrometric analysis. J Conserv Dent. 2018 Sep-Oct;21(5):516-520.Pubmed PMID: 30294113.

[8]. Malli Sureshbabu N, Selvarasu K, V JK, Nandakumar M, Selvam D. Concentrated Growth Factors as an Ingenious Biomaterial in Regeneration of 
Bony Defects after Periapical Surgery: A Report of Two Cases. Case Rep Dent. 2019 Jan 22;2019:7046203.Pubmed PMID: 30805222.

[9]. Kaufman AY, Fuss Z, Keila S, Waxenberg S. Reliability of different electronic apex locators to detect root perforations in vitro. Int Endod J. 1997 Nov;30(6):403-7.

[10]. Govindaraju L, Neelakantan P, Gutmann JL. Effect of root canal irrigating solutions on the compressive strength of tricalcium silicate cements. Clin Oral Investig. 2017 Mar;21(2):567-571.Pubmed PMID: 27469101.

[11]. WolfTG, Krauß-Mironjuk A, Wierichs RJ, Briseńo-Marroquín B. Influence of embedding media on the accuracy of working length determination by means of apex locator: an ex vivo study. Sci Rep. 2021 Feb 8;11(1):3340. Pubmed PMID: 33558636.

[12]. Rajakeerthi R, Nivedhitha MS. Natural Product as the Storage medium for an avulsed tooth-A Systematic Review. Cumhur. Dent. J. 2019 Jun $11 ; 22(2): 249-56$.

[13]. Aguiar BA, Reinaldo RS, Frota LM, do Vale MS, de Vasconcelos BC. Root ZX Electronic Foramen Locator: An Ex Vivo Study of Its Three Models' Precision and Reproducibility. Int J Dent. 2017;2017:1-4.Pubmed PMID: 28367215.

[14]. Saraf PA, Ratnakar P, Patil TN, Penukonda R, Kamatagi L, Vanaki SS. A comparative clinical evaluation of accuracy of six apex locators with intraoral periapical radiograph in multirooted teeth: An in vivo study. J Conserv Dent. 2017 Jul-Aug;20(4):264-268.Pubmed PMID: 29259365.

[15]. Taneja S, Kumar M, Sharma SS, Gogia H. Comparative evaluation of accuracy of three electronic apex locators in different simulated clinical conditions-an invitro study. Ann Med Health Sci Res. 2017;7(3)

[16]. Manohar MP, Sharma S. A survey of the knowledge, attitude, and awareness about the principal choice of intracanal medicaments among the general dental practitioners and nonendodontic specialists. Indian J Dent Res. 2018 Nov-Dec;29(6):716-720.Pubmed PMID: 30588997.

[17]. Estrela C, Decurcio DD, Rossi-Fedele G, Silva JA, Guedes OA, Borges ÁH. Root perforations: a review of diagnosis, prognosis and materials. Brazilian oral research. 2018 Oct 18;32(suppl 1):e73.

[18]. Hegde M, Varghese L, Malhotra S. Tooth root perforation repair-A review. oral health dent. manag. 2017;16(2):1-4.

[19]. Siddique R, Sureshbabu NM, Somasundaram J, Jacob B, Selvam D. Qualitative and quantitative analysis of precipitate formation following interac- tion of chlorhexidine with sodium hypochlorite, neem, and tulsi. J Conserv Dent. 2019 Jan-Feb;22(1):40-47.Pubmed PMID: 30820081.

[20]. Janani K, Sandhya R. A survey on skills for cone beam computed tomography interpretation among endodontists for endodontic treatment procedure. Indian J Dent Res. 2019 Nov-Dec;30(6):834-838.Pubmed PMID: 31939356.

[21]. Saed SM, Ashley MP, Darcey J. Root perforations: aetiology, management strategies and outcomes. The hole truth. Br Dent J. 2016 Feb;220(4):171180.

[22]. Aidasani GL, Mulay S. Management of iatrogenic errors: Furcal perforation. J Int Clin Dent Res Organ. 2018 Jan 1;10(1):42.

[23]. Teja KV, Ramesh S, Priya V. Regulation of matrix metalloproteinase-3 gene expression in inflammation: A molecular study. J Conserv Dent. 2018 Nov;21(6):592-6.

[24]. Siddique R, Nivedhitha MS. Effectiveness of rotary and reciprocating systems on microbial reduction: A systematic review. J Conserv Dent. 2019 Mar;22(2):114-22

[25]. Muthu MS, Sivakumar N. Accuracy of electronic apex locator in length determination in the presence of different irrigants: An in vitro study. J Indian Soc Pedod Prev Dent. 2006 Oct 1;24(4):182.

[26]. Connert T, Judenhofer MS, Hülber-J M, Schell S, Mannheim JG, Pichler $\mathrm{BJ}$, et al. Evaluation of the accuracy of nine electronic apex locators by using Micro-CT. Int Endod J. 2018 Feb;51(2):223-232.Pubmed PMID: 28675449.

[27]. Azeem RA, Sureshbabu NM. Clinical performance of direct versus indirect composite restorations in posterior teeth: A systematic review. J Conserv Dent. 2018 Jan;21(1):2-9.

[28]. Khandelwal A, Palanivelu A. Correlation between dental caries and salivary albumin in adult population in Chennai: An in vivo study. Braz. Dent. Sci. 2019 Apr 30;22(2):228-33.

[29]. Ferreira I, Braga AC, Pina-Vaz I. The Precision of Propex Pixi with Different Instruments and Coronal Preflaring Procedures. Eur Endod J. 2019 Jul 10;4(2):75-79.Pubmed PMID: 32161891.

[30]. Ramarao S, Sathyanarayanan U. CRA Grid - A preliminary development and calibration of a paper-based objectivization of caries risk assessment in undergraduate dental education. J Conserv Dent. 2019 Mar-Apr;22(2):185-190. Pubmed PMID: 31142991. 